\title{
Psychosocial Issues for Adolescent and Young Adult Cancer Patients in a
}

Global Context: A Forward-Looking Approach

Nina Jackson Levin, MSW, ${ }^{1 *}$ Bradley Zebrack, $\mathrm{PhD},{ }^{2}$ Steve W. Cole, $\mathrm{PhD}^{3}$

${ }^{1}$ School of Social Work and Department of Anthropology, University of Michigan ${ }^{2}$ School of Social Work, University of Michigan

${ }^{3}$ David Geffen School of Medicine, University of California Los Angeles

${ }^{*}$ Correspondence to:

Nina Jackson Levin, 1080 S. University, Room B660, Ann Arbor, MI 48109-1106 248-229-6557, ninalev@umich.edu

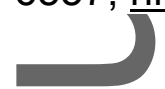

Abstract Word Count: 150

Main TextWord-Count (excluding headings and sub-headings): 3,383

Tables: 2

Figures: 0

Supplemental Files: 0

Key words: AYA, adolescent, young adult, psychosocial needs, cancer, global context

\begin{tabular}{|l|l|}
\hline Abbreviation & Full phrase \\
\hline AYA & Adolescent and young adult \\
\hline
\end{tabular}

This abstract was previously submitted and accepted for poster presentation at the $3^{\text {rd }}$ Annual Adolescent and Young Adult Cancer Congress in Sydney, Australia, 5 December 2018.

The authors state no conflict of interest.

Data sharing is not applicable to this article as no new data were created or analyzed in this study.

This is the author manuscript accepted for publication and has undergone full peer review but has not been through the copyediting, typesetting, pagination and proofreading process, which may lead to differences between this version and the Version of Record. Please cite this article as doi: 10.1002/pbc.27789.

This article is protected by copyright. All rights reserved. 


\begin{abstract}
The first decade of AYA oncology psychosocial care and research (20052015) was driven by a normative, developmental framework that assumed a
\end{abstract} generalizable life experience for AYAs that is distinct from both younger children and older aduits. As we proceed through a second decade, new considerations emerge regarding diversity of life experiences as occurring within and influenced by a complex global context. The purpose of this paper is to review and provide commentary on the impact of global and contextual conditions on AYAs. We expound upon the effects of precarious labor conditions, changing timetables and priorities for developmental tasks, sexual and gender plurality, and expanding cultural diversity. We discuss the implications of social genomics and technology and social media for enhancing precision psychosocial medicine. To build a forwardlooking approach, this paper calls for tailored, multilevel treatments that consider variability of AYAs within the social and global contexts in which they live.

Introduction

Bleyer's seminal report on adolescents and young adults with cancer, ${ }^{1}$ the United States' National Cancer Institute's subsequent establishment of an Adolescent and Young Adult (AYA) Oncology Progress Review Group, ${ }^{2}$ the advancement of practice guidelines and policy statements for AYAs globally, ${ }^{3,4,5}$ and an emergent body of empirical literature all distinguish an age-defined population of cancer patients age 15-39 from both older and younger patient populations. These activities have brought warranted attention to a vulnerable and underserved population. 
Encountering cancer during a developmentally precarious time can complicate the experiences typical to this life phase: developing independence - both emotional and financial; cultivating self-confidence, self-sufficiency, and sense of identity; pursuing education, vocation, or career; experiencing social and romantic intimacy; and making sexual and reproductive choices appropriate to young adulthood. Reconciling disappointment in the thwarted vision for one's future and confronting mortality at such a young age can be particularly devastating to AYAs. Patients in this age group therefore differ from younger children and older adults diagnosed with cancer, especially in terms of psychosocial needs. This remains true throughout a continuum of care that initiates with diagnosis and persists through phases of active treatment and transitions to post-treatment survivorship or, in many cases, the end of life. ${ }^{6}$

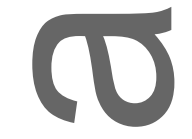

Literature in the first decade of AYA research primarily reflects the distinct developmental challenges of AYA patients. Between 2005 and 2015, AYA psychosocial needs were examined with conventional and chronological developmental frameworks (e.g., Erikson's Stage Theory; ${ }^{7}$ Arnett's Emerging Adulthood Theory4/23/2019 10:21:00 AM). In looking toward the future of AYA oncology, however, formulating an accurate representation of AYA psychosocial needs requires an understanding of the current social and global environment in which young people are maturing today. The purpose of this manuscript is to examine knowledge and evidence of the effects of a changing global context on AYA efficacy to manage cancer and its treatment while also confronting the daily challenges associated with psychological maturation, growth, and development (See Table 1 for Key Points). 


\section{Understanding the AYA Experience in a Global Context}

In this manuscript, we elaborate upon Hammond's (2016) framework for understanding the AYA experience within a global context and draw upon empirical literature that accounts for social and contextual conditions of AYA cancer. ${ }^{9}$ This framework considers (1) precarious labor conditions affecting AYA financial and work lives; (2) changing timetables and priorities for developmental tasks; (3) sexual and gender plurality, and (4) expanding cultural diversity of AYA. ${ }^{9}$ We extend this framework to incorporate two additional aspects of relevance for understanding AYA psychosocial issues: (5) social genomics; and (6) technology and social media (See Table 2).

(1) Precarious labor conditions affecting AYA financial and work lives Young people in today's global economy face labor markets that offer decreasing job security and increasing financial vulnerability. ${ }^{9}$ The coupling of higher costs of living, lower minimum wage (adjusted for inflation) and the changing nature of career-building and employment opportunities have risks for financial distress among all young people over the past 30 years, ${ }^{9}$ let alone those confronting physical or mental health issues or disabilities that further limit their employment opportunities.

A cancen diagnosis comes with significant costs that fall outside the purview of covered medical care. Even if AYAs have access to public, private, or employmentbased health insurance, the out-of-pocket expenses of cancer quickly become exorbitant: for example, lost income from missed work, delayed progress toward academic and professional degrees, transportation expenses to and from treatment 
centers. ${ }^{10,11}$ While cancer patients of all ages frequently incur debt during treatment and survivorship, ${ }^{12}$ these financial setbacks are differentially experienced by AYAs. Not only does cancer hoist an imminent daunting financial burden onto AYAs early in life, it also stifles development of financial autonomy for the future. AYAs undergoing cancer treatment may become more dependent on their family as payers for their care at a time in life when they are trying to establish independence. This contradiction can have adverse psychosocial impacts on educational, vocational, and employment success as well as on self-esteem, self-confidence, and sense of independence. ${ }^{13}, 14,11$

Based on nationally representative data, Guy et al. (2014) estimate that survivors incur an excess annual medical expenditure of $\$ 3,170$ per person and an excess annual productivity loss of $\$ 2,250$ per person. This dynamic disproportionately affects AYAs from lower socioeconomic backgrounds, who as a result, may betess likely to sustain continuity of ongoing care and consequently experience higher rates of morbidity, mortality and worse quality of life. ${ }^{10,12}$ Equipping AYAs to overcome potential risks to economic uncertainty, therefore, must be considered integral to AYA care. Oncology social workers often play an essential role in mitigating this financial burden by linking AYAs with resources that include but are not limited to assisting AYAs to qualify for loans, employer-funded or state-based disability programs, local sources for financial and vocational counseling, job training programs, or pharmaceutical companies' compassionate use programs to offset or discount excessive costs of chemotherapeutics.

(2) Changing timetables and priorities for developmental tasks 
Any upper and lower age parameters defined for AYAs assume a homogeneity of experience with regard to theoretically-derived stages of human development. Theories of human development suggest that phases of adolescence and young adulthood are distinct and replete with key developmental milestones including developing an identity of self, constructing a personal set of standards and values, establishing a positive body image, becoming independent from parents, gaining autonomy, establishing interpersonal and romantic relationships, attaining intimacy, achieving a sexual identity, and making decisions about studies, a profession, or starting a family. ${ }^{15}$ Reaching these benchmarks is often considered a sign of health and success, whereas falling short of these milestones is regarded as regression or delay in normative development. ${ }^{16}$

A narrative that emphasizes setbacks in this prescribed timeline may not reflect the true changing nature of current AYA psychological and social development, or the diversity of developmental trajectories across population sub-groups defined by race/ethnicity, sex/gender, sexual orientation, local cultural context, or religion.

In today's global context, there are indications that young people are choosing to depart from traditional milestones. They are electing to live with their parents longer, waiting longer for (or never pursuing) marriage and children, and working multiple (contingent or part-time) jobs related to their different interests. ${ }^{9}$ While cancer often heightens AYA attachment to their parents for emotional support and assistance with medical decision making, framing this behavior as deviant or regressive is not helpful or accurate. Developmental trajectories in the general adolescent population are changing due to evolving social conditions that characterize this phase. As a result, it is advantageous for the care team to move away from the goal of achieving an assumed linear developmental trajectory and instead establish goals for AYA 
patients that reflect their own personal values and preferences. This shift in expectations can be cultivated through interpersonal conversations about building goals that are unique to each AYA.

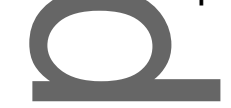

(3) Sexual and gender plurality

Sex, sexuality, gender identity, and fertility are separate and distinct topics that are often confounded in regard to AYAs. Among these, clinical attention to fertility is emphasized, and rightfully so given evidence of unmet oncofertility needs reported by AYAs. ${ }^{17,18}$ However, addressing and distinguishing AYA needs with regard to sexual function, behavior, sexual orientation and gender identification are less well understood. AYAs today live in a culture where sexual practices and gender identities are expressive and fluid, where goals for relationships and children cannot be assumed based upon conventional definitions of what constitutes "family."

An emphasis on recovery of the physical body from cancer can often eclipse other psychological developmental concerns of relevance for the adolescent, including the resolution of tensions, contradictions, and complexities of puberty. ${ }^{19}$ Complications with the development of gender identity and healthy sexuality have lifelong ramifications such as relationship difficulties. The care team must attend to the sex and gender related needs of this group. While there is scant literature that emphasizes best practices for supporting sexual/gender identity development and AYAs, there is a growing literature on both fertility preservation and lesbian, gay, bisexual, transgender and queer (LGBTQ) patient care. ${ }^{20}$ Assuring that at least one member of the care team is apprised of this literature is critical. The care team must foster relationships with AYAs in which they can express and garner relevant and appropriate information about issues at the nexus of cancer and sexuality. 
(4) Expanding cultural diversity of AYA

AYA patient

AYA patient population is bound and defined by age, yet the demographic characteristics within this group are often disregarded, leading to clinical care and programs that privilege some and exclude others in that the programmatic structure or content is not aligned with patient and family values, preferences, or culturallyimbued beliefs. Defining the AYA population solely in terms of age and phases of human development and not accounting for the cultural diversity within the population can perpetuate implicit biases that infuse and inform clinical and programmatic approaches to care.

Addressing cultural diversity and providing equitable care requires that care providers take the time to understand how and why patients and families act and respond the way they do. Bahrami et al. $(2017)^{21}$ provide the example of Iranian families who resist talking openly with loved ones about disease and prognosis, and the challenges that the care team faces in working with parents who withhold crucial information from their children due to culturally-derived beliefs. Conversations with AYAs around their life goals and personal beliefs can help to overcome the anxiety, tension or distrust that AYAs often bring to their encounters with oncology care providers. A holistic understanding of patients' and families' choices and behaviors strengthens the therapeutic relationship, builds trust, and enables patients and providers to work together to establish clinical care goals that address their mutual concerns. 


\section{(5) Social Genomics}

Research in 'adult oncology has begun to examine how cancer patients' experiences of their lives and disease affect the biology of cancer, and how the biological impacts of cancer and its treatment reciprocally impact patient experience, well-being, and survivorship. Some of this research has emerged in the context of "social genomics" studies, which analyze the pathways by which psychological, social, cultural, economic, and other life circumstances influence the expression of human genes throughout the body, and in particular in cancer cells. ${ }^{22,}{ }^{23}$ For example, clinical studies of breast, ovarian, and prostate cancer patients suggest that those who feel socially isolated and lack social support show accelerated disease progression relative to those who feel more socially enmeshed and supported. 24, 25,26 Analyses of tumor tissues from such patients have found increased expression of a wide array of genes involved in inflammation, blood vessel growth, and metastasis, as well as reduced expression of genes involved in antitumor immune responses. ${ }^{22,23,27}$ Laboratory studies have documented similar results in animal models of solid tumors and leukemia and have identified increased activity of fight-or-flight signaling molecules as key biological mediators of these effects. ${ }^{22,} 23,27$ Similar studies of circulating white blood cells have also documented systematic increases in expression of inflammatory genes and decreases in expression of antiviral (Type I interferon) genes in people confronting a diverse array of adverse life circumstances including poverty, post-traumatic stress, chronic loneliness, low social status, and immanent bereavement. ${ }^{28,}{ }^{29}$ Additional research has shown that activation of inflammatory genes in somatic tissues can signal back to the brain to stimulate negative emotional states, reduce social motivation, and impair problem-solving skills. ${ }^{30,31}$ Together, these lines of research indicate a bi- 
directional feedback loop between psychosocial conditions and molecular processes involved in cancer progression and treatment. More broadly, this research provides a molecular framework for mapping the biological pathways through which the social determinants of health at the macro level ultimately impact disease pathogenesis at the microlevel. ${ }^{22,23}$

A smaltbody of research has also begun to examine the effects of positive psychological and social resources in buffering genomic responses to adversity. For example, personal psychological resilience was found to reduce the association between trauma exposure and gene expression alterations in former Nepali child soldiers. ${ }^{32}$ Studies have also found more favorable leukocyte gene expression profiles (reduced inflammatory signaling and increased interferon-related gene expression) in leukocytes from people with a strong sense of purpose in life ${ }^{33,34,35}$ and pro-social engagement. ${ }^{36}$

Little is known about the social genomics of AYA cancer. Given the dynamic and diverse developmental processes taking place during this period and their long-term implications for adult well-being trajectories, as well as the extended periods of survivorship that many AYA cancer patients will experience, there is a great need to examine these reciprocal biopsychosocial relationships. Emerging research on the biological correlates of psychological resilience also has clear relevance for cancer patients as theycope with the psychosocial impact of a life-threatening disease. The clinical and economic impacts of social genomic relationships have not yet been explored and represent important topics for future research. Cancer social genomics research has so far analyzed psychosocial processes solely through the lens of academically-defined constructs and meaning systems; however, other social genomics studies have begun to use more ethnographic approaches to define 
personally or culturally valid meaning spaces that shape reciprocal interactions between mind and body. ${ }^{32,37}$ Given the diversity of cancer patient experiences and AYA developmental trajectories, it will be important to utilize such idiographic and ethnographic research strategies in mapping the embodied experience of cancer.

(6) Technology and social media

In today's highly digitized world, the role of technology and social media is integral to the everyday activities of the majority of teens and YAs. Information circulation, interpersonal communication, and self-expression all fall under the purview of the digital context. While this claim may seem obvious, discrete knowledge about AYA media engagement, with its particular implications for treatment, still requires in-depth investigation as to its utility and clinical benefit. There are two general lines of inquiry that define the current state of research into AYA media use: medical information seeking and peer connection/community building. The overlap between these two is in the potential for AYAs to provide reflexive, peer-generated knowledge about their own experiences as an online resource to other AYAs.

Since most AYAs have internet access, the online space can appear as a helpful buttress to physician-provided information. While knowledge about disease has been correlated with enduring adherence to medical care and follow-up treatment, the majority of AYAs using online search engines often find the information impenetrable and untrustworthy. ${ }^{38}$ Many AYAs use their phones and computers to search for unanswered medical questions; the answers they find are often inaccurate or irrelevant to their case. ${ }^{21}$ Domínguez and Sapiña $(2017)^{38}$ provide insight into the search behaviors of AYAs seeking online medical information 
related to their diagnoses and treatments. ${ }^{38}$ Most AYAs seek information about the physical and psychological consequences of their diseases, as well as drug affects, follow-up care procedures, and iatrogenic infertility. It may be important for AYAs to take time-in private to read about their condition and its effects, especially as it relates to uncomfortable topics like sexuality and fertility. ${ }^{19}$

Such trends indicate that AYAs routinely seek information beyond that which the medical team provides and therefore medical providers must proactively curate AYA specific content. AYAs express desire for accessible, accurate information, especially if their doctors have an impersonal online presence or social media profile that generates treatment related updates and information (through posts and hashtags): ${ }^{38}$ Additionally, AYAs express desire for forums to meet peers, but indicate that forums specific to their conditions are often difficult to find. ${ }^{16}$ Perales et al. $(2016)^{39}$ offer a catalog of resources for blogs, forums, and online communities. These sites generate informational resources and a palliative community-building tools but also as a potential database for AYA driven research. Used in moderation, technology may be an optimal resource already available at many AYAs' fingertips.

\section{DISCUSSION: Toward an AYA global context}

Psychosocial care for cancer patients in the clinical setting most often involves an individualized therapeutic approach following initial engagement and assessment. Referring patients for psychosocial interventions when clinically indicated is absolutely necessary as part of quality care delivery but is often inadequate. In general, multilevel public health interventions that address patient as well as social and environmental context have a greater likelihood for success. Given the global characteristics of AYA needs articulated in this paper, we suggest that 
care of AYAs may be enhanced through newfound emphasis on three discrete domains: (1) Multilevel interventions and collaborative care approaches; (2) Precision Psychosocial Medicine; and (3) Technology and information.

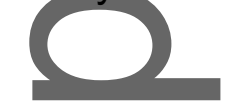

(1) Multilevel Interventions and Collaborative Care Approaches

Multilevel Interventions and Collaborative Care Approaches call for patienttailored treatment programs that operate simultaneously on intrapersonal, interpersonal, and community or organizational levels. Otherwise put, a single point of intervention can only function optimally within a broader network of rehabilitative structures and practices. In this expansive framework, it is particularly incumbent upon oncologists to identify and utilize psychosocial and behavioral resources within their own institution or community. For example, Pini et al. $(2016 ; 2012)^{40,41}$ examine effective strategies for integrating AYA educational support systems between parents, peers, teachers, and medical providers. Similarly, Fong et al. $(2015)^{42}$ demonstrate that cancer survivors in the adult population are four times more likely to be employed if they receive vocational support services such as training and job searching. Interventions targeting emotional healing must be matched by attention to practical considerations such as financial constraints, culturally informed preferences or restrictions, and unique every day activities of each AYA. This multilevel approach enables the care team to treat patients as whole people living with cancer in a complex global context.

(2) Precision Psychosocial Medicine

The ultimate goal of precision medicine is to get the "right" treatment to the "right" patient at the "right" time in the "right" dose. We suggest that a precision 
psychosocial care model similarly accounts for individual behavior and outcomes in the context of a broad social environment in order to personalize care and thus offer programs and services to those AYA patients having the highest probability for benefiting from those services. A precision medicine framework is applicable for guiding biomedical as well as psychosocial care for cancer patients of all ages. Understanding host conditions and context - be they biologic, psychologic, or social is critical for delivering precision medicine. As we have demonstrated here, there is no one-size-fits-all intervention for AYAs; therefore, it is incumbent upon clinicians to continuously screen and assess psychosocial needs over time, particularly at the transition from treatment to off-treatment survivorship. ${ }^{43}$ These assessments must consider broad variation in experiences that factor into a treatment plan for each patient. Social genomics accounts for social and environmental context as part of the algorithm for determining and delivering therapies in cases having the highest known probability for success. Furthermore, Precision Psychosocial Medicine as a framework functions well within a multilevel modality: intervening upon a biopsychosocial feedback loop at multiple points has the potential to enhance effectiveness of treatment in multiple simultaneous domains.

\section{(3) Technology and Information}

Given the pervasiveness of social media and online activity, moving into the future of AYA care calls for innovative and relevant uses of digital technologies. AYAs demonstrate a prevalence of online information seeking behaviors regarding disease and treatment as well as a preference for psychosocial support from peers. Such behavior presents an opportunity for medical providers to channel well-guided treatment information to AYAs. The care team should exploit the tools of social 
media for good by curating age-appropriate, culturally-sensitive content that educates, informs, and empowers AYAs about their cancer. Some of the topics this content may cover include but are not limited to: fertility options and consequences, identity development including sexual identity, financial resources during treatment, post-treatment medical surveillance and care, and other hospital-specific information such as local events, activities, and opportunities of interest. Furthermore, social media tools not only serve as an informational channel between the care team and patients but also as a resource for peer-generated support, AYA data collection, and AYA driven research. While many online forums already exist for AYAs, the care team must organize and leverage these platforms for delivering accurate, appropriate medical and psychosocial content.

\section{CONCLUSION}

As AYA oncology care and research enters a second decade (its adolescence), treatment may be improved by pivoting toward a more expansive inclusivity and its consequent implications for both precision psychosocial support and interyention. Recognizing that the AYA patients' day-to-day lives outside the hospital are inextricable from their cancer care experiences in the hospital, the care team must aim for tailored interventions that account for broad variations within and across a diverse AYA population. The scope of AYA domain contexts is vast. This manuscript provides a survey of topics relevant to the global context of AYAs and the future of AYA care. The issues articulated here serve less as comprehensive analyses of each sociodemographic context and more as cairns for the future of AYA psychosocial research and clinical care. 
Table 1: Key Points

Key Points,

- AYA oncology patients are a distinct age-defined population (15-39 years). There are multiple and varied biological, psychological and social factors besides age that make this patient population distinct.

- This paper identifies (6) domains that characterize this group:

(1) Precarious global financial conditions affecting AYA financial and work lives

(2) Changing timetables and priorities for developmental tasks

(3) Sexual and gender plurality

(4) Expanding cultural diversity of AYA

(5) Social Genomics

(6) Technology and social media

- This article calls for oncology care providers to take a forward-looking approach regarding these domains. We suggest focusing practice modifications on (3) areas:

(1) Multilevel Interventions and Collaborative Care Approaches

(2) Precision Psychosocial Medicine

(3) Technology and Information

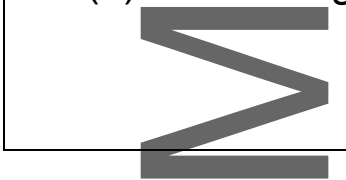

Table 2: AYA Global Contexts, Examples, and Suggested Interventions ${ }^{1}$

\begin{tabular}{|c|c|c|c|c|c|c|}
\hline & (1) & (2) & (3) & (4) & (5) & (6) \\
\hline શિ & $\begin{array}{l}\text { Precarious } \\
\text { labor condition } \\
\text { affecting AYA } \\
\text { financial and } \\
\text { work lives }\end{array}$ & $\begin{array}{l}\text { Changing } \\
\text { timetables and } \\
\text { priorities for } \\
\text { developmental } \\
\text { tasks }\end{array}$ & $\begin{array}{l}\text { Sexual and } \\
\text { gender plurality }\end{array}$ & $\begin{array}{l}\text { Expanding } \\
\text { cultural } \\
\text { diversity of } \\
\text { AYA }\end{array}$ & $\begin{array}{l}\text { Social } \\
\text { Genomics }\end{array}$ & $\begin{array}{l}\text { Technology } \\
\text { and social } \\
\text { media }\end{array}$ \\
\hline 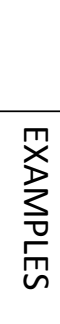 & $\begin{array}{l}\text { AYAs are } \\
\text { particularly } \\
\text { vulnerable to } \\
\text { confronting } \\
\text { financial } \\
\text { hardship dur } \\
\text { and after } \\
\text { treatment. }\end{array}$ & $\begin{array}{l}\text { The demands of } \\
\text { confronting } \\
\text { cancer during } \\
\text { adolescence } \\
\text { can often } \\
\text { reroute 'typical' } \\
\text { developmental } \\
\text { milestones. }\end{array}$ & $\begin{array}{l}\text { AYAs undergo } \\
\text { cancer } \\
\text { concurrently } \\
\text { with sexual and } \\
\text { gender identity } \\
\text { formation. }\end{array}$ & $\begin{array}{l}\text { AYA is } \\
\text { heralded as } \\
\text { distinct } \\
\text { because of its } \\
\text { age range, yet } \\
\text { cultural } \\
\text { diversity within } \\
\text { that group is }\end{array}$ & $\begin{array}{l}\text { AYA period is } \\
\text { particularly } \\
\text { dynamic } \\
\text { biologically } \\
\text { and } \\
\text { psychosocially }\end{array}$ & $\begin{array}{l}\text { Technology } \\
\text { and social } \\
\text { media are } \\
\text { integrated } \\
\text { activities into } \\
\text { lifestyles of } \\
\text { AYAs. Many } \\
\text { use these tools }\end{array}$ \\
\hline
\end{tabular}

\section{${ }^{1}$ Adapted from Hammond (2016)}

This article is protected by copyright. All rights reserved. 


\begin{tabular}{|c|c|c|c|c|c|c|}
\hline & & & & $\begin{array}{l}\text { often } \\
\text { disregarded. }\end{array}$ & & $\begin{array}{l}\text { to seek and } \\
\text { share cancer- } \\
\text { related } \\
\text { information. }\end{array}$ \\
\hline 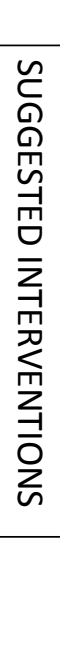 & $\begin{array}{l}\text { Care team } \\
\text { must connect } \\
\text { AYAs to local } \\
\text { financial } \\
\text { resources as } \\
\text { an integral } \\
\text { function of the } \\
\text { treatment plan }\end{array}$ & $\begin{array}{l}\text { AYAs in the } \\
\text { general } \\
\text { population are } \\
\text { redefining the } \\
\text { typical } \\
\text { developmental } \\
\text { trajectory. Care } \\
\text { team can } \\
\text { encourage } \\
\text { patients to frame } \\
\text { their cancer as } \\
\text { part of this new } \\
\text { move toward } \\
\text { individualized } \\
\text { developmental } \\
\text { trajectories. }\end{array}$ & $\begin{array}{l}\text { Care team } \\
\text { must work to } \\
\text { foster } \\
\text { relationships } \\
\text { between AYAs } \\
\text { and care team } \\
\text { members in } \\
\text { which they can } \\
\text { express and } \\
\text { garner } \\
\text { information } \\
\text { about issues at } \\
\text { the nexus of } \\
\text { cancer and } \\
\text { sexuality. }\end{array}$ & $\begin{array}{l}\text { Care team } \\
\text { must attend } \\
\text { thoroughly to } \\
\text { language, } \\
\text { religious } \\
\text { values, and } \\
\text { diverse racial } \\
\text { identities } \\
\text { among AYAs. }\end{array}$ & $\begin{array}{l}\text { Social } \\
\text { genomics } \\
\text { research on } \\
\text { AYA cancer is } \\
\text { needed to } \\
\text { inform } \\
\text { treatment } \\
\text { recommendati } \\
\text { ons and } \\
\text { formulate new } \\
\text { approaches to } \\
\text { promote } \\
\text { resilience. }\end{array}$ & $\begin{array}{l}\text { Care team } \\
\text { should provide } \\
\text { digital } \\
\text { resources to } \\
\text { educate } \\
\text { patients about } \\
\text { their cancer as } \\
\text { well as provide } \\
\text { spaces to } \\
\text { express } \\
\text { themselves and } \\
\text { connect with } \\
\text { peers. } \\
1\end{array}$ \\
\hline
\end{tabular}

Conflict of Interest: The authors declare no conflict of interest.

Acknowledgements: Nina Jackson Levin is supported by a Graduate Student Research Assistantship Award from the University of Michigan School of Social Work.

\section{References}

1. Bleyer A, O'Leary M, Barr R, Reis L. Cancer Epidemiology in Older Adolescents and Young Adults 15 to 29 Years of Age, Including SEER Incidence and Survival: 1975-2000. Bethesda, MD: National Cancer Institute, NIH Pub; 2006.

2. Adolescent and Young Adult Oncology Progress Review Group: Closing the Gap: Research and Care Imperatives for Adolescents and Young Adults with Cancer. Department of Health and Human Services, National Institutes of Health, National Cancer Institute, and the LiveStrong Young Adult Alliance; 2006.

3. CanTeen Australia. Australian Youth Cancer Framework for Adolescents and Young Adults with Cancer.; 2017. 
4. Sam S, Mooney S, Cable M, Taylor RM. The Blueprint of Care for Teenagers and Young Adults with Cancer. London: Teenage Cancer Trust; 2016.

5. Coccia PF, Altman J, Bhatia S, et al. Adolescent and young adult oncology. Clinical practice guidelines in oncology. J Natl Compr Canc Netw. 2012:10(9):1112-1150.

6. Kaal SE., Husson O, Duivenboden S van, et al. Empowerment in adolescents and young adults with cancer: Relationship with health-related quality of life. Cancer. 2017;123(20):4039.

7. Erikson EH. Childhood and Society. 1st ed. New York: Norton; 1950.

8. Arnett JJ.Emerging adulthood: A Theory of development from the late teens through the twenties. American Psychologist. 2000;55(5):469-480. doi: $10.1037 / / 0003-066 X .55 .5 .469$

9. Hammond C. Against a Singular Message of Distinctness: Challenging DominantRepresentations of Adolescents and Young Adults in Oncology. Journal of Adolescent and Young Adult Oncology. 2016;6(1):45-49. doi:10.1089/jayao.2016.0018

10. Fardell JE, Wakefield CE, Patterson P, et al. Narrative Review of the Educational, Vocational, and Financial Needs of Adolescents and Young Adults with Cancer: Recommendations for Support and Research. Journal of Adolescent and Young Adult Oncology. 2018;7(2):143.

11. Zebrack $B$, Isaacson S. Psychosocial care of adolescent and young adult patients with cancer and survivors. J Clin Oncol. 2012;30(11):1221-1226. doi:10.1200/JCO.2011.39.5467

12. Tucker-Seeley RD, Yabroff KR. Minimizing the "Financial Toxicity" Associated with Cancer Care: Advancing the Research Agenda. Journal of the National Cancer Institute. 2016;108(5).

13. Kosola S, McCarthy MC, McNeil R, Orme LM, Drew S, Sawyer SM. Early Education and Employment Outcomes After Cancer in Adolescents and Young Adults. Journal of Adolescent and Young Adult Oncology. 2018;7(2):238.

14. Smits-Seemann RR, Yi J, Tian T, Warner EL, Kirchhoff AC. A Qualitative Inquiry of Childhood and Adolescent Cancer Survivors' Perspectives of Independence. Journal of Adolescent and Young Adult Oncology. 2016;6(1):91-95. doi:10.1089/jayao.2016.0022

15. Belpame N, Kars MC, Beeckman D, et al. "The AYA Director": A Synthesizing Concept to Understand Psychosocial Experiences of Adolescents and Young Adults With Cancer. Cancer Nursing. 2016;39(4):292.

16. Docherty SL, Kayle M, Maslow GR, Santacroce SJ. The Adolescent and Young Adult with Cancer: A Developmental Life Course Perspective. Seminars in Oncology Nursing. 2015;31(3):186-196. doi:10.1016/j.soncn.2015.05.006 
17. McCarthy MC, McNeil R, Drew S, Orme L, Sawyer SM. Information needs of adolescent and young adult cancer patients and their parent-carers. Supportive Care in Cancer. 2018;26(5):1655.

18. Wettergren L, Kent EE, Mitchell SA, et al. Cancer negatively impacts on sexual function in adolescents and young adults: The AYA HOPE study. Psychooncology, Psycho-oncology, Psycho-Oncology. 2017;26(10):1632-1639. doi:10.1002/pon.4181

19. Moules N, Estefan A, Laing C, et al. "A Tribe Apart": Sexuality and Cancer in Adolescence. Journal of Pediatric Oncology Nursing. 2017;34(4):295.

20. M. Russell A, Galvin KM, Harper MM, Clayman ML. A comparison of heterosexual and LGBTQ cancer survivors' outlooks on relationships, family building, possible infertility, and patient-doctor fertility risk communication. Journal of Cancer Survivorship. 2016;10(5):935.

21. Bahrami $M$, Namnabati $M$, Mokarian $F$, Oujian $P$, Arbon $P$. Information-sharing challenges between adolescents with cancer, their parents and health care providers: a qualitative study. Supportive Care in Cancer. 2017;25(5):15871596

22. Antoni $\mathrm{MH}$, Lutgendorf SK, Cole SW, et al. The influence of bio-behavioural factors on tumour biology: pathways and mechanisms. Nat Rev Cancer. 2006,6(3):240-248. doi:10.1038/nrc1820

23. Cole SW.Nervous system regulation of the cancer genome. Brain Behav Immun. 2013;30 Suppl:S10-18. doi:10.1016/j.bbi.2012.11.008

24. Lutgendorf SK, De Geest K, Bender D, et al. Social influences on clinical outcomes of patients with ovarian cancer. J Clin Oncol. 2012;30(23):2885-2890. doi:10.1200/JCO.2011.39.4411

25. Kroenke $\mathrm{CH}$, Kubzansky LD, Schernhammer ES, Holmes MD, Kawachi I. Social networks, social support, and survival after breast cancer diagnosis. J Clin Oncol. 2006;24(7):1105-1111. doi:10.1200/JCO.2005.04.2846

26. Jan M, Bonn SE, Sjölander A, et al. The roles of stress and social support in prostate cancer mortality. Scand J Urol. 2016;50(1):47-55. doi:10.3109/21681805.2015.1079796

27. Cole SW, Nagaraja AS, Lutgendorf SK, Green PA, Sood AK. Sympathetic nervous system regulation of the tumour microenvironment. Nat Rev Cancer. 2015;15(9):563-572. doi:10.1038/nrc3978

28. Cole SW. Human social genomics. PLoS Genet. 2014;10(8):e1004601. doi:10.1371/journal.pgen.1004601

29. Cole SW. Social regulation of human gene expression: mechanisms and implications for public health. Am J Public Health. 2013;103 Suppl 1:S84-92. doi:10.2105/AJPH.2012.301183 
30. Eisenberger NI, Moieni M, Inagaki TK, Muscatell KA, Irwin MR. In Sickness and in Health: The Co-Regulation of Inflammation and Social Behavior.

Neuropsychopharmacology. 2017;42(1):242-253. doi:10.1038/npp.2016.141

31. Dantzer R, O'Connor JC, Freund GG, Johnson RW, Kelley KW. From inflammation to sickness and depression: when the immune system subjugates the brain Nat Rev Neurosci. 2008;9(1):46-56. doi:10.1038/nrn2297

32. Kohrt BA, Worthman CM, Adhikari RP, et al. Psychological resilience and the gene regulatory impact of posttraumatic stress in Nepali child soldiers. Proc Natl Acad Sci USA. 2016;113(29):8156-8161. doi:10.1073/pnas.1601301113

33. Fredrickson BL, Grewen KM, Coffey KA, et al. A functional genomic perspective on human well-being. Proc Natl Acad Sci USA. 2013;110(33):13684-13689.

doi:10.1073/pnas.1305419110

34. Kitayama S, Akutsu S, Uchida Y, Cole SW. Work, meaning, and gene regulation: Findings from a Japanese information technology firm.

Psychoneuroendocrinology. 2016;72:175-181.

doi:10.1016/j.psyneuen.2016.07.004

35. Fredrickson BL, Grewen KM, Algoe SB, et al. Psychological well-being and the human conserved transcriptional response to adversity. PLoS ONE.

2015:10(3):e0121839. doi:10.1371/journal.pone.0121839

36. Netson-Coffey SK, Fritz MM, Lyubomirsky S, Cole SW. Kindness in the blood: A randomized controlled trial of the gene regulatory impact of prosocial behavior. Psychoneuroendocrinology. 2017;81:8-13. doi:10.1016/j.psyneuen.2017.03.025

37. Snodgrass, JG, Dengha III HJF, Lacy MG, et al. Social Genomics of Healthy and Disordered Internet Gaming. In Press. 2018.

38. Dominguez M, Sapina L. "Others Like Me". An Approach to the Use of the Internet and Social Networks in Adolescents and Young Adults Diagnosed with Cancer. Journal of Cancer Education. 2017;32(4):885.

39. Perales M-A, Drake EK, Pemmaraju N, Wood WA. Social Media and the Adolescent and Young Adult (AYA) patient with Cancer. Current hematologic malignancy reports. 2016;11(6):449-455. doi:10.1007/s11899-016-0313-6

40. Pini S Peter|Hugh-Jones, Siobhan. The impact of a cancer diagnosis on the education engagement of teenagers - Patient and staff perspective. European Journal of Oncology Nursing. 2012;17(3):317.

41. Pini S, Gardner P, Hugh-Jones S. How teenagers continue school after a diagnosis of cancer: experiences of young people and recommendations for practice. Future Oncology. 2016;12(24):2785.

42. Murphy KM, Westbrook JD, Markle MM. Psychological Interventions to Facilitate Employment Outcomes for Cancer Survivors Psychological Interventions to Facilitate Employment Outcomes for Cancer 
Survivors: A Systematic Review and Meta-Analysis

A Systematic Review and Meta-Analysis. Research on Social Work Practice. 2018;28(1):84-98. doi:10.1177/1049731515604741

43. Walsh C, Currin-McCulloch J, Simon P, Zebrack B, Jones B. Shifting Needs and Preferences: Supporting Young Adult Cancer Patients During the Transition from Active Treatment to Survivorship Care. Journal of Adolescent and Young Adult Oncology. October 2018. doi:10.1089/jayao.2018.0083

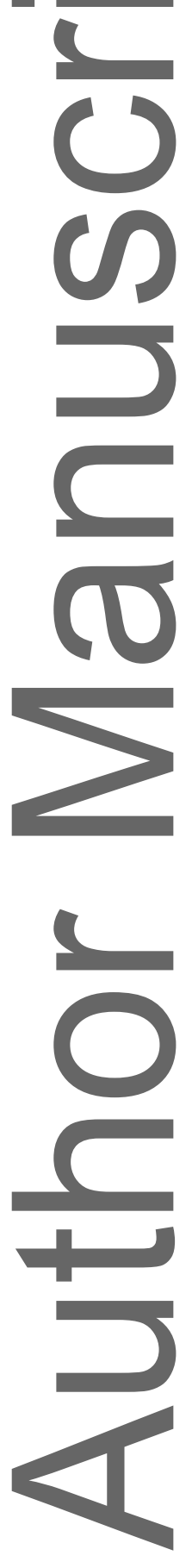

